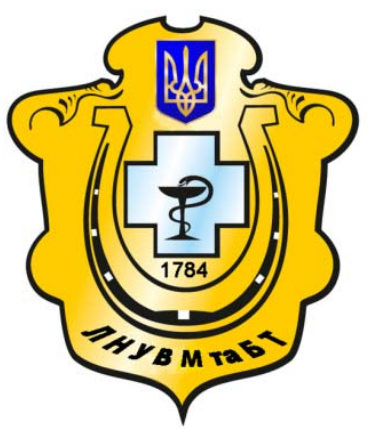

Науковий вісник Львівського національного університету ветеринарної медицини та біотехнологій імені С.3. Гжицького

Scientific Messenger of Lviv National University of Veterinary Medicine and Biotechnologies named after S.Z. Gzhytskyj

doi:10.15421/nvlvet7143

ISSN 2413-5550 print

ISSN 2518-1327 online

$\underline{\text { http://nvlvet.com.ua/ }}$

УДК 619:616.995.1:636.1

\title{
Порівняльна оцінка дії нового препарату з відомим аналогом у експерименті на лабораторній культурі мух родини Calliphoridae
}

\author{
А.М. Шевченко \\ shevchenko@brovafarma.com.ua \\ ТОВ «Бровафарма», \\ бульв. Незалежності, 18-а, м Бровари, Київська обл., 07400, Україна
}

\begin{abstract}
У статті наведено дані щъодо порівняльної оцінки впливу нового препарату Мухо-Мор з відомим аналогом у експерименті на лабораторній культурі мух родини Calliphoridae. Враховуючи швидке виникнення резистентності у членистоногих до інсектииидів, запропоновано ввести у якості АДР нову для ринку сполуку альфаметрин та, як основну принаду, мускалур (иис-9-трикозен). В якості тест-препарату для перевірки залишкової дії на різних тест-об'єктах нового лікарського засобу Мухо-Мор був обраний інсектицид Флай-Байт, який на ринку ветеринарних засобів в Украйні впевнено зайняв місие лідера за якістю та ефективністю.

Встановлено, шо експериментальний зразок препарату Мухо-Мор проявив тривалу залишкову дію на лабораторну культуру мух виду Lисіlia sericata. Так, на шестидесяту добу, його летальна дія за експозиції однієї години на скляній та дерев'яній поверхнях складала 16,7 та 17,8\%, відповідно і була в 1,87 та 1,6 рази вищою, ніж у експерименті з ФлайБайтом. Через три години спостерігалась 100\% загибель всіх комах, щзо контактували з Мухо-Мором.

Протягом всього експерименту новий інсектииид проявляв виражений нокдаун-ефект, у стані якого знаходилось від 74,4 до 84,4\% мух при експозииії однієї години. За наступні дві години всі комахи гинули. Разом з тим,на скляних тестповерхнях протягом однієї години контакту комах з Мухо-Мором до п'ятидесятої доби його летальна дія була кращою, ніж на дерев'яних.
\end{abstract}

Ключові слова: інсектицид, Мухо-Мор, Флай-Байт, атрактант, мускалур, альфаметрин, лабораторна культура мух, каліфориди, тест-об'єкт.

\section{Сравнительная оценка действия нового препарата с известным аналогом в экспериментах на лабораторной культуре мух семейства Calliphoridae}

\author{
А.Н. Шевченко \\ shevchenko@brovafarma.com.ua \\ ООО «Бровафарма», \\ бульв. Независимости, 18-а, г. Бровары, Киевская обл., 07400, Украина
}

\begin{abstract}
В статье приведены данные сравнительной оценки влияния нового препарата Мухо-Мор с известным аналогом в эксперименте на лабораторной культуре мух семейства Calliphoridae. Учитывая быстрое возникновение резистентности у членистоногих к инсектииидам, предложено ввести в качестве АДВ новое для рынка соединение альфаметрин и, как основную приманку, мускалур (иис-9-трикозен). В качестве тест-препарата для проверки остаточного действия на различных тест-объектах нового лекарственного средства Мухо-Мор был избран инсектииид Флай Байт, который на рынке ветеринарных средств в Украине уверенно занял место лидера по качеству и эффективности.

Установлено, что экспериментальный образец препарата Мухо-Мор проявил длительное остаточное действие на лабораторную культуру мух вида Lucilia sericata. Так, на шестидесятые сутки, его летальное действие при экспозиции одного часа на стеклянной и деревянной поверхностях составляла 16,7 и 17,8\%, соответственно и была в 1,87 и 1,6 раза выше,
\end{abstract}

Citation:

Shevchenko, A. (2016). Comparative evaluation of the action of new preparation mucho-mor with a well-known analogue in the experiment on laboratory culture of flies family calliphoridae. Scientific Messenger LNUVMBT named after S.Z. Gzhytskyj, 18, 3(71), 190-194. 
чем в эксперименте с Флай Байтом. Через три часа наблюдалась 100\% гибель всех насекомых, которые контактировали с Мухо-Мором.

В течение всего эксперимента новый инсектицид проявлял выраженный нокдаун-эффект, в состоянии которого находилось от 74,4 до 84,4\% мух при экспозиции одного часа. За следуюшие два часа все насекомые погибали. Вместе с тем, на стеклянных тест-поверхностях в течение одного часа контакта насекомых с Мухо-Мором с пятидесятых суток его летальное действие было лучше, чем на деревянных.

Ключевые слова: инсектицид, Мухо-Мор, Флай Байт, аттрактант, мускалур, альфаметрин, лабораторная культура мух, калифориды, тест-объект.

\title{
Comparative evaluation of the action of new preparation mucho-mor with a well-known analogue in the experiment on laboratory culture of flies family calliphoridae
}

\author{
A. Shevchenko \\ shevchenko@brovafarma.com.ua \\ «Brovapharma»Ltd, \\ Nezalezhnosti blvd., 18-A, Brovary, Kyiv region, 07400, Ukraine
}

The article presents data on comparative evaluation of action of the new preparation Mucho-Mor with the well-known analogue in the experiment on laboratory culture of flies of the Calliphoridae family. Considering rapid emergence of resistance to insecticides in arthropods, it is suggested to introduce a new to the market alphamethrin compound as an active agent, and muscalur (cis9-Tricosene) as the main attractant. An insecticide Fly Byte was selected as a test-drug for analysis of residual effects on different test sited, which is known as a leading product on the Ukrainian veterinary market for its quality and efficiency.

It was established that the experimental sample of the drug Mucho-Mor showed a lasting residual action on laboratory culture of the flies Lucilia sericata. Thus, on the $6^{\text {th }}$ day its lethal effect with the exposure for one hour on the glass and wooden surfaces was 16.7 and $17.8 \%$, respectively, and was by 1.87 and 1.6 times higher compared to the experiment with Fly Bite. After three hours was observed $100 \%$ morbidity of all insects, which contacted with Mucho-Mor.

Throughout the experiment, the new insecticide showed a pronounced knockdown effect, which affected $74.4-84.4 \%$ flies in the exposure of one hour. During the next two hours all the insects died. However, the lethal effect on the glass test surfaces was better than on the wooden surface up to the $50^{\text {th }}$ day of exposure.

Key words: insecticide, Mucho-Mor, Fly Byte, attractant, muscalur, alphamethrin, laboratory culture of flies, calliphoridae, test object.

\section{Вступ}

Протягом тривалого часу літаючі комахи були i залишаються неабиякою проблемою для людини в багатьох сферах життєдіяльності, знижуючи якість продукції та послуг, спричиняючи значні економічні збитки у тваринництві (Isimbekov et al., 2010; Nepoklonov et al., 2011).

Однак, незважаючи на значну їх поширеність, науковці й досі не створили єдину глобальну стратегію боротьби 3 ними. Так, для протидії паразитичним комахам запропоновано механічні, фізичні, хімічні та біологічні методи (Bodreeva et al., 1982; Verbyc'kyj and Dostojevs'kyj, 2004).

Серед хімічних методів, принади для мух залишаються одним 3 найбільш безпечних і раціональних способів застосування інсектицидів (Carlson et al., 2000).

Сьогодні на вітчизняному ринку ветеринарних інсектицидних принад присутні:

- інсектицидний засіб «Квік Байт ВГ 10», виробник «Квізда Агро ГмбХ», Австрія, на основі імідаклоприду - інсектициду, що належить до групи хлорнікотиніловихсполук;

- інсектицидний засіб «Флай Байт», виробник «Денка Інтернешнл», Нідерланди, на основі метомілу - інсектициду, що належить до групи карбамату;
- інсектицидний засіб «Агіта $10 \mathrm{WG»,} \mathrm{виробник}$ «Новартіс», Словенія, на основі тіаметоксаму, з групи неонікотиноїдів (Gorzheev, 2013).

Однак, ряд науковців вказують на швидке виникнення резистентності у членистоногих до інсектицидів (Roslavceva, 2008). Тому, нами запропоновано ввести у якості АДР нову для ринку сполуку альфаметрин, що $є$ типовим представником синтетичних піретроїдів другого покоління 3 вираженою контактношлунковою інсектицидною дією. Як основну принаду у цьому новому засобі використано мускалур (цис-9трикозен), що є статевим феромоном самки домашньої мухи (Musca domestica) та комплекс із допоміжних принад - етанол та ароматизатор сиру.

В якості носія служили суміші сорбітолу і лактози (4:1), що допомогло поліпшити показники поїдання інсектициду комахами. Крім того, введення гіркоти бітрексу, дозволило попередити поїдання розкладеної принади тваринами та домашньою і синантропною птицею.

Таким чином, створено композицію із трьох видів принад, яка повинна забезпечувати стійку та тривалу атрактивну спроможність на фоні високих інсектицидних властивостей.

Подібним за своїми характеристиками на ринку ветеринарних засобів виявився препарат Флай Байт, який в останні роки впевнено зайняв місце лідера за 
якістю та своєю ефективністю серед засобів направлених на знищення комах (Gorzheev, 2013).

Саме тому, в якості тест-препарату для перевірки залишкової дії на різних тест-об'єктах нового лікарського засобу Мухо-Мор був обраний саме інсектицид Флай Байт, який для порівняння теж використовувався у зволоженому вигляді.

\section{Матеріал і методи досліджень}

Дослідження проводили в умовах лабораторії ТОВ «АкроВетЛаб» - спільної українсько-голландської компанії, що займається науково-дослідною діяльністю та проводить клінічні випробування і лабораторний аналіз нових ветеринарних препаратів для їх подальшої реєстрації. Як тест-об'єкти використовували скляні та дерев'яні поверхні, які на початку досліду обробляли суспензіями препаратів Мухо-Мор та Флай Байт і поміщали в окремі спеціальні садки. Після підсаджування лабораторної культури мух виду
Lucilia sericata через одну годину проводили їх підрахунок. Визначали кількість живих, мертвих та у стані «нокдаун-ефекту» каліфорид. За комахами спостерігали ще дві години. У кожній групі використовували три повтори. Всього під час експерименту було використано 5400 особин лабораторної культури мух виду Lucilia sericata.

\section{Результати та їх обговорення}

У першій серії досліду Мухо-Мор та Флай Байт помістили на скляні тест-поверхні. Порівнюючи летальну дію яких виявлено, що до 50-ї доби експерименту включно, за годину експозиції, смертність серед комах досліду спостерігалась у 2-7,16 разів вищою при їх контакті з Флай-Байтом На 60-ту добу спостерігалась різка зміна прояву інсектицидної дії нового препарату. В цей період домінуючим був нокдаун ефект у стані якого знаходилось 78,9 \% комах (табл. 1).

Таблиця 1

Активність препаратів Мухо-Морта Флай Байт на скляній поверхні

\begin{tabular}{|c|c|c|c|c|}
\hline Доба досліджень & Статус & Контроль & Мухо-Мор & Флай-Байт \\
\hline \multirow{3}{*}{ Доба 0} & живі & $30 \pm 0$ & $1,67 \pm 0,10$ & $0,67 \pm 0,10$ \\
\hline & нокдаун & 0 & $24,00 \pm 0,46$ & $5,00 \pm 0,15$ \\
\hline & мертві & 0 & $4,33 \pm 0,40$ & $24,33 \pm 0,20$ \\
\hline \multirow{3}{*}{ Доба 1} & живі & $30 \pm 0$ & $1,67 \pm 0,10$ & $1,00 \pm 0,15$ \\
\hline & нокдаун & 0 & $22,33 \pm 0,96$ & $2,67 \pm 0,25$ \\
\hline & мертві & 0 & $6,00 \pm 0,91$ & $26,33 \pm 0,10$ \\
\hline \multirow{3}{*}{ Доба 3} & живі & $30 \pm 0$ & $1,33 \pm 0,10$ & $1,00 \pm 0,15$ \\
\hline & нокдаун & 0 & $24,67 \pm 0,40$ & $0,33 \pm 0,10$ \\
\hline & мертві & 0 & $4,00 \pm 0,46$ & $28,67 \pm 0,20$ \\
\hline \multirow{3}{*}{ Доба 7} & живі & $30 \pm 0$ & $1,00 \pm 0,15$ & $1,00 \pm 0,30$ \\
\hline & нокдаун & 0 & $23,33 \pm 0,41$ & $0,33 \pm 0,10$ \\
\hline & мертві & 0 & $5,67 \pm 0,36$ & $28,67 \pm 0,25$ \\
\hline \multirow{3}{*}{ Доба 14} & живі & $30 \pm 0$ & $1,33 \pm 0,10$ & $1,33 \pm 0,10$ \\
\hline & нокдаун & 0 & $24,33 \pm 0,25$ & $1,00 \pm 0,30$ \\
\hline & мертві & 0 & $4,33 \pm 0,25$ & $27,67 \pm 0,25$ \\
\hline \multirow{3}{*}{ Доба 21} & живі & $30 \pm 0$ & $1,33 \pm 0,25$ & $3,00 \pm 0,30$ \\
\hline & нокдаун & 0 & $24,33 \pm 0,41$ & $3,00 \pm 0,46$ \\
\hline & мертві & 0 & $4,33 \pm 0,56$ & $24,00 \pm 0,15$ \\
\hline \multirow{3}{*}{ Доба 30} & живі & $30 \pm 0$ & $1,33 \pm 0,10$ & $3,67 \pm 0,10$ \\
\hline & нокдаун & 0 & $24,67 \pm 0,25$ & $4,00 \pm 0,61$ \\
\hline & мертві & 0 & $4,00 \pm 0,15$ & $22,33 \pm 0,56$ \\
\hline \multirow{3}{*}{ Доба 40} & живі & $30 \pm 0$ & $2,33 \pm 0,10$ & $2,67 \pm 0,25$ \\
\hline & нокдаун & 0 & $23,33 \pm 0,20$ & $10,33 \pm 0,10$ \\
\hline & мертві & 0 & $4,33 \pm 0,25$ & $17,00 \pm 0,30$ \\
\hline \multirow{3}{*}{ Доба 50} & живі & $30 \pm 0$ & $1,00 \pm 0,15$ & $4,67 \pm 0,51$ \\
\hline & нокдаун & 0 & $25,33 \pm 0,10$ & $18,00 \pm 0,61$ \\
\hline & мертві & 0 & $3,67 \pm 0,10$ & $7,33 \pm 0,25$ \\
\hline \multirow{3}{*}{ Доба 60} & живі & $30 \pm 0$ & $1,00 \pm 0,15$ & $3,67 \pm 0,36$ \\
\hline & нокдаун & 0 & $24,00 \pm 0,15$ & $23,67 \pm 0,36$ \\
\hline & мертві & 0 & $5,00 \pm 0,30$ & $2,67 \pm 0,20$ \\
\hline
\end{tabular}

Більш стабільну дію проявив Мухо-Мор, який протягом всього часу спостережень проявляв летальну дію на комах від 13,3 до 20\%. При цьому, на шестидесяту добу ця дія була в 1,87 рази кращою, ніж у Флай-Байту, коли протягом однієї години загинуло $16,67 \%$ лабораторних мух.

Оцінюючи показник нокдаун ефекту дії інсектицидів на комах спостерігали значну відмінність його прояву серед мух, що контактували з скляною повер- хнею обробленою Флай-Байтом до тридцятої доби, включно, та пізніше. Так, якщо в перший місяць експерименту виявляли в середньому від 0,33 до 5,00 комах у стані нокдаун ефекту, то з сорокової доби їх кількість зросла в 2,06 рази до 10,33 особин, а на кінець експерименту складала 78,9\% таких комах у групі.

Слід відмітити, що експериментальний зразок препарату Мухо-Мор, протягом всього експерименту 
проявляв виражений нокдаунефект, у стані якого знаходилось від 74,4 до 84,4\% мух, що контактували 3 інсектицидом.

Порівняння залишкової дії інсектицидів надерев'яних дощечках показало, що протягом години експозиції смертність серед комах спостерігалась у 4,85 - 10,66 разів вищою при їх контакті з ФлайБайтом до сорокової доби експерименту, включно (табл. 2).
На п’ятидесяту добу спостерігалась різка зміна прояву інсектицидної дії цього препарату. В цей період домінуючим став нокдаун ефект у стані якого знаходилось 78,9\% комах.

Разом 3 тим, більш стабільну дію проявив МухоМор, який протягом всього часу спостережень проявляв летальну дію на комах від 6,7 до 17,8\%. При цьому, на 50 добу ця дія була в 1,4, а на 60 - в 1,6 рази вищою, ніж у Флай Байту, коли протягом однієї години загинуло 15,6 та $17,8 \%$ лабораторних мух, відповідно.

Таблиияя 2

Активність препаратів Мухо-Мор та Флай Байт на дерев'яній поверхні

\begin{tabular}{|c|c|c|c|c|}
\hline Доба досліджень & Статус & Контроль & Мухо-Мор & Флай-Байт \\
\hline \multirow{3}{*}{ Доба 0} & Живі & $30 \pm 0$ & $3,33 \pm 0,10$ & $3,00 \pm 0,15$ \\
\hline & Нокдаун & 0 & $24,67 \pm 0,20$ & $5,67 \pm 0,25$ \\
\hline & Мертві & 0 & $2,00 \pm 0,15$ & $21,33 \pm 0,20$ \\
\hline \multirow{3}{*}{ Доба 1} & Живі & $30 \pm 0$ & $0,67 \pm 0,10$ & $2,67 \pm 0,25$ \\
\hline & Нокдаун & 0 & $23,67 \pm 0,20$ & $3,00 \pm 0,15$ \\
\hline & Мертві & 0 & $4,33 \pm 0,40$ & $24,33 \pm 0,10$ \\
\hline \multirow{3}{*}{ Доба 3} & Живі & $30 \pm 0$ & $3,67 \pm 0,36$ & $2,67 \pm 0,10$ \\
\hline & Нокдаун & 0 & $22,00 \pm 0,30$ & $5,00 \pm 0,15$ \\
\hline & Мертві & 0 & $4,33 \pm 0,56$ & $22,33 \pm 0,25$ \\
\hline \multirow{3}{*}{ Доба 7} & Живі & $30 \pm 0$ & $1,33 \pm 0,10$ & $2,00 \pm 0,15$ \\
\hline & Нокдаун & 0 & $24,00 \pm 0,61$ & $5,33 \pm 0,20$ \\
\hline & Мертві & 0 & $4,67 \pm 0,51$ & $22,67 \pm 0,25$ \\
\hline \multirow{3}{*}{ Доба 14} & Живі & $30 \pm 0$ & $0,67 \pm 0,10$ & $4,00 \pm 0,15$ \\
\hline & Нокдаун & 0 & $26,00 \pm 0,15$ & $3,67 \pm 0,25$ \\
\hline & Мертві & 0 & $3,33 \pm 0,10$ & $22,33 \pm 0,41$ \\
\hline \multirow{3}{*}{ Доба 21} & Живі & $30 \pm 0$ & $1,00 \pm 0,15$ & $4,00 \pm 0,15$ \\
\hline & Нокдаун & 0 & $25,67 \pm 0,10$ & $5,00 \pm 0,15$ \\
\hline & Мертві & 0 & $3,33 \pm 025$ & $21,00 \pm 0,30$ \\
\hline \multirow{3}{*}{ Доба 30} & Живі & $30 \pm 0$ & $1,00 \pm 0$ & $6,33 \pm 0,56$ \\
\hline & Нокдаун & 0 & $26,00 \pm 0,30$ & $5,67 \pm 0,10$ \\
\hline & Мертві & 0 & $3,00 \pm 0,30$ & $18,00 \pm 0,46$ \\
\hline \multirow{3}{*}{ Доба 40} & Живі & $30 \pm 0$ & $0,67 \pm 0,10$ & $3,00 \pm 0,15$ \\
\hline & Нокдаун & 0 & $25,33 \pm 0,10$ & $8,67 \pm 0,41$ \\
\hline & Мертві & 0 & $4,00 \pm 0,15$ & $18,33 \pm 0,25$ \\
\hline \multirow{3}{*}{ Доба 50} & Живі & $30 \pm 0$ & $1,33 \pm 0,10$ & $3,00 \pm 0,30$ \\
\hline & Нокдаун & 0 & $24,00 \pm 0,30$ & $23,67 \pm 0,36$ \\
\hline & Мертві & 0 & $4,67 \pm 0,20$ & $3,33 \pm 0,10$ \\
\hline \multirow{3}{*}{ Доба 60} & Живі & $30 \pm 0$ & $1,00 \pm 0,15$ & $8,33 \pm 0,81$ \\
\hline & Нокдаун & 0 & $23,67 \pm 0,20$ & $18,33 \pm 0,56$ \\
\hline & Мертві & 0 & $5,33 \pm 0,25$ & $3,33 \pm 0,25$ \\
\hline
\end{tabular}

До тридцятої доби, включно, та пізніше спостерігали значну відмінність прояву нокдаун-ефекту при контакті комах з Флай Байтом на дерев'яній поверхні. Так, якщо в перший місяць експерименту виявляли в середньому від 3,0 до 5,67\% комах у стані нокдаун ефекту, то з сорокової доби їх кількість зросла на $52,9 \%$ до 8,67 особин, а на 50 та 60 добу експерименту вже складала 78,9 та $61,1 \%$ таких комах у групі, відповідно.

Мухо-Мор, протягом всього експерименту проявляв виражений нокдаун ефект, у стані якого знаходилось від 73,3 до 86,7\% мух, що контактували з інсектицидом.

Разом 3 тим, на час останніх спостережень, через три години виявляли 100\% загибель комах у садках зі скляною та дерев'яною поверхнями, оброблених Мухо-Мором. Натомість, змін стану комах на третю годину контакту з Флай Байтом не виявляли.
При підсаджуванні мух виду Lucilia sericata до пустих садків, що служили контролем, змін у поведінці та випадків загибелі протягом шестидесяти діб досліджень не спостерігали.

\section{Висновки}

1. Експериментальний зразок препарату МухоМор проявив тривалу залишкову дію на лабораторну культуру мух виду Lucilia sericata. На 60 добу його летальна дія за експозиції однієї години на скляній та дерев'яній поверхнях складала 16,7 та 17,8\% відповідно, і була в 1,87 та 1,6 рази вищою, ніж у експерименті з Флай-Байтом. Через три години спостерігалась $100 \%$ загибель всіх комах, що контактували з МухоМором.

2. Мухо-Мор, протягом всього експерименту проявляв виражений нокдаун-ефект, у стані якого знахо- 
дилось від 74,4 до 84,4\% мух при експозиції однієї години. За наступні дві години всі комахи гинули.

3. Летальна дія Мухо-Мору протягом однієї години контакту комах з ним на скляній поверхні до 50 доби спостережень, була вищою, ніж на дерев'яній.

Перспективи подальших досліджень. В наступних дослідженнях планується провести оцінку ефективності інсектицидної дії новоствореного препарату Мухо-Мор у виробничих умовах.

\section{Бібліографічні посилання}

Isimbekov, Zh.M. Madieva K.M., Utenova G.M., Nasyrova F.S. (2010). Muhi (Diptera, Cyclorrhapha) nekotoryh mest Pavlodarskogo Priirtysh'ja. Vestnik PGU: nauchnyj zhurnal Pavlodarskogo gos. un-ta im. S. Torajgyrova. 3, 137-142 (in Russian).

Nepoklonov, A.A., Prohorova, I.A., Mavrin, N.A. (2011). Bor'ba s podkozhnymi ovodami i profilaktika gipodermatoza krupnogo rogatogo skota v Rossii i za rubezhom. Veterinarija Kubani. 5.- URL: http://www.vetkuban.com/num5_20117.html (in Russian).

Verbyc'kyj, P.I., Dostojevs'kyj, P.P. (2004). Dovidnyk likarja veterynarnoi' medycyny. K.: Urozhaj, 395-397 (in Ukrainian).
Bodreeva, L.A. Ignat'ev, V.I., Kuznecov, V.D. (1982). Ajerozoli neocidola - jeffektivnoe sredstvo bor'by $\mathrm{s}$ muhami $\mathrm{v}$ zhivotnovodcheskih pomeshhenijah. IV Vsesojuznaja konferencija po ajerozoljam: Tezisy dokladov. Erevan, 10-11 (in Russian).

Salmon, J.K., Armgtoong, C.A., Ansel, J.C. (1994). The skin as an immune organ. Western Jorurnal of Medicine. 160, 146-152.

Kuznecov, V.D., Kotljar, V.I. (1983). Dezinsekcija v uslovijah svinokompleksa. Veterinarnaja jentomologija i akarologija. M.: Kolos. 1, 135-137 (in Russian).

Carlson, D.A., Alzogarayand, A., Jerome, A. (2000). Hogsette Behavi oral Response of Stomoxys calcitrans (Diptera: Muscidae) to Conspecific Fecesand Feces Extracts. Journal of Medical Entomology. 37(6), 957961.

Gorzheev, V.M. (2013). Dovidnyk veterynarnyh preparativ. L'viv: «Afisha» (in Ukrainian).

Roslavceva, S.A. (2008). Opasnost' formirovanija rezistentnosti $\mathrm{k}$ insektoakaricidam $\mathrm{u}$ perenoschikov vozbuditelej infekcionnyh zabolevanij. Dezdelo. 2, 52-56 (in Russian).

Стаття надійшла до редакиії 27.09.2016 